\title{
$\triangle F 508$ CFTR protein expression in tissues from patients with cystic fibrosis
}

\author{
Nanette Kälin, ${ }^{1}$ Andreas Claaß, ${ }^{2}$ Martin Sommer, ${ }^{2}$ Edith Puchelle, ${ }^{3}$ and Burkhard Tümmler ${ }^{1}$ \\ ${ }^{1}$ Klinische Forschergruppe Molekulare Pathologie der Mukoviszidose, Medizinische Hochschule Hannover, D-30623 Hannover, \\ Germany \\ ${ }^{2}$ Department of Pediatrics, University of Kiel, D-24105 Kiel, Germany \\ ${ }^{3}$ Institut National de la Santé et de la Recherche Médicale, Unité 314, Université de Reims, F-51092 Reims Cédex, France
}

Address correspondence to: Nanette Kälin, Klinische Forschergruppe Molekulare Pathologie der Mukoviszidose, PO Box 610180, OE 6711, Medizinische Hochschule Hannover, D-30623 Hannover, Germany. Phone: 49-511-532-2920; Fax: 49-511-532-6723; E-mail: Kaelin.Nanette@MH-Hannover.de.

Received for publication November 6, 1998, and accepted in revised form March 23, 1999.

Heterologous expression of the cystic fibrosis transmembrane conductance regulator (CFTR) provided evidence that the major cystic fibrosis (CF) mutation $\triangle \mathrm{F} 508$ leads to defective protein folding in the endoplasmic reticulum, which prevents its processing and targeting to the cell surface. In this study, we investigated endogenous CFTR expression in skin biopsies and respiratory and intestinal tissue specimens from $\triangle \mathrm{F} 508$ homozygous and non-CF patients, using immunohistochemical and immunoblot analyses with a panel of CFTR antibodies. CFTR expression was detected at the luminal surface of reabsorptive sweat ducts and airway submucosal glands, at the apex of ciliated cells in pseudostratified respiratory epithelia and of isolated cells of the villi of duodenum and jejunum, and within intracellular compartments of intestinal goblet cells. In $\Delta \mathrm{F} 508$ homozygous patients, expression of the mutant protein proved to be tissue specific. Whereas $\Delta$ F508 CFTR was undetectable in sweat glands, the expression in the respiratory and intestinal tracts could not be distinguished from the wild-type by signal intensity or localization. The tissue-specific variation of $\triangle \mathrm{F} 508 \mathrm{CFTR}$ expression from null to apparently normal amounts indicates that $\triangle \mathrm{F} 508$ CFTR maturation can be modulated and suggests that determinants other than CFTR mislocalization should play a role in $\triangle \mathrm{F} 508 \mathrm{CF}$ respiratory and intestinal disease.

J. Clin. Invest. 103:1379-1389 (1999).

\section{Introduction}

Cystic fibrosis $(\mathrm{CF})$ is characterized by defective hydration of exocrine secretions, resulting in mucus plugging in the affected organs, and involves pancreatic insufficiency and chronic airway infections as the major clinical manifestations. The severe autosomal-recessive condition is caused by mutations in the cystic fibrosis transmembrane conductance regulator gene (CFTR), which encodes an epithelial low-conductance chloride channel. Of more than 800 identified CFTR mutations the 3-bp in-frame deletion of codon 508 is found worldwide in $70 \%$ of CF chromosomes, thus making $\triangle$ F508 CFTR the most common lethal mutant in Caucasian populations (1).

The analysis of $\triangle \mathrm{F} 508$ CFTR in different heterologous systems revealed an abrogation of CFTR expression by defective protein maturation. Mutant CFTR was found arrested in an early wild-type intermediate, unable to adopt a protease-resistant mature conformation (2-4) that enables exit from the endoplasmic reticulum (ER) and processing in the Golgi compartment. A prolonged interaction of immature $\triangle \mathrm{F} 508 \mathrm{CFTR}$ with the chaperones calnexin (5) and hsp70 (6) indicated the recognition of the aberrant protein by the cell's quality control and resulted in premature degradation in a pre-Golgi compartment by the ubiquitin-proteasome pathway (7-9). Reduction of temperature (10) and addition of chemical chaperones such as glycerol (11) and trimethylamine- $N$-oxide (12) overcame impediments in the folding pathway of $\Delta$ F508 CFTR and allowed proper target- ing, demonstrating that the mutant protein is still capable of assuming a mature conformation. However, at the cell surface the chloride channel revealed a decreased half-life $(13,14)$ and reduced open probability and sensitivity to stimulation with cAMP agonists $(10,15-17)$.

In contrast to the in-depth analysis of the molecular basis of the $\triangle F 508$ CFTR defect in heterologous model systems, only very little data describe the impact of impaired processing on the mutant phenotype of CF tissues. The loss of immunohistochemical detectability of $\triangle$ F508 CFTR in sweat glands and submucosal glands of the larger airways are the only data that substantiated a generalized protein-folding defect in the disease situation $(18,19)$. In this study, $\Delta F 508$ CFTR expression was investigated in the CF-affected respiratory epithelia and submucosal glands, in the intestine, and in sweat glands, and revealed tissue-specific processing of the mutant protein that ranged from an apparent wild-type-like situation to the abrogation of CFTR expression in CF patients. These findings suggest that overcoming the barrier of ER quality control alone will not be sufficient to cure the $\Delta \mathrm{F} 508 \mathrm{CF}$ defect in the patient.

\section{Methods}

Tissue samples

Eccrine sweat glands. Skin biopsies were taken from the right shoulder of 5 healthy volunteers, $4 \Delta \mathrm{F} 508$ homozygous CF patients, and $3 \mathrm{CF}$ patients homozygous for the stop mutations $\operatorname{R553X}(n=1)$ and G542X $(n=2)$. 
Nasal polyps. CFTR immunoblot analysis was performed on 20 non-CF and $12 \Delta \mathrm{F} 508$ homozygous CF nasal polyps, from which CFTR immunoblot analysis gave positive results in 5 non-CF and $6 \Delta \mathrm{F} 508$ homozygous CF specimens. CFTR immunohistochemistry was carried out on an overlapping panel of nasal polyp tissue specimens ( 8 non-CF and $10 \Delta \mathrm{F} 508$ homozygous CF specimens).

Submucosal glands. Submucosal glands were investigated from 1 non-CF and $1 \Delta$ F508 homozygous CF nasal polyp and in bronchial tissue specimens from 3 non-CF and $3 \Delta \mathrm{F} 508$ homozygous CF lung explants.

Intestinal tissue specimens. For immunohistochemistry, the expression of CFTR was analyzed in $7 \Delta$ F508 homozygous tissue specimens taken from 3 newborn patients with meconium ileus and 4 adult patients who required surgical intervention because of meconium ileus equivalent. Five newborn patients with different obstruction syndromes (e.g., gastroschisis and exclusion of the mutation $\Delta \mathrm{F} 508$ ), as well as 2 adult cancer patients, were taken as non-CF controls. CFTR immunoblot analysis was performed on a subgroup of $3 \Delta \mathrm{F} 508$ homozygotes and 7 non-CF patients, both groups consisting of newborn and adult patients. Rectal suction biopsies were taken from 4 non$\mathrm{CF}$ and $2 \mathrm{CF}$ patients, one of whom was homozygous for $\Delta \mathrm{F} 508$; the other was homozygous for the deletion of exons 2 and 3 . Explicit consent was obtained from each individual.

Analysis of the mutation $\triangle F 508$. The deletion of a phenylalanine at position 508 was determined by heteroduplex analysis (20).

CFTR antibodies. The rabbit polyclonal antibody PAC13 was raised against a synthetic peptide corresponding to amino acid 1468-1480 (KEETEEEVQDTRL) of the COOH-terminus of CFTR. Generation of the antibodies and purification were essentially as described by Marino et al. (21). The antibody PAC865 was generated by using an Escherichia coli recombinant glutathione-S-transferase fusion protein of amino acid 1202-1422 of the second nucleotide-binding fold (NBF) of CFTR. The protein was purified from inclusion bodies, solubilized in $8 \mathrm{M}$ urea and $2 \%$ SDS, and isolated prior to immunization from preparative polyacrylamide gels (22). Both antisera were purified by immunoaffinity chromatography with the CFTR antigen, which was coupled to activated Affi-Gel 10 agarose columns (Bio-Rad

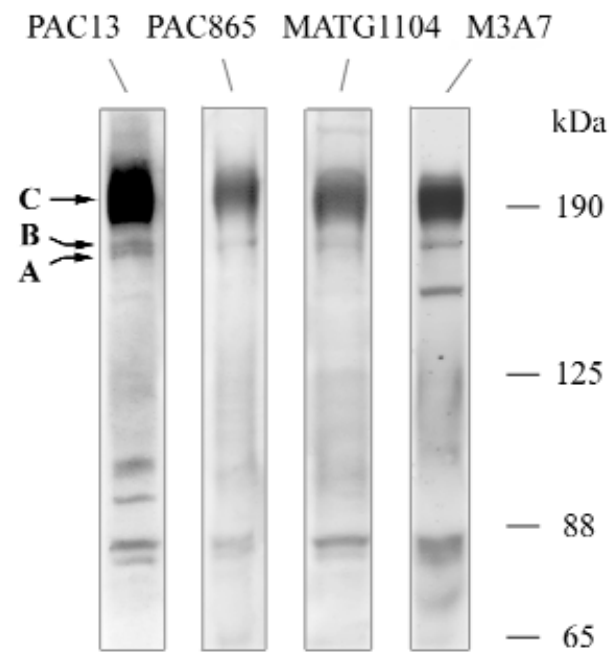

\section{Figure 1}

CFTR antibodies PAC13, PAC865, MATG1104, and M3A7 detect the characteristic immunoreactive CFTR bands in immunoblot analysis of 84 cells. Band C refers to mature, complex-glycosylated CFTR; band B to the immature, core-glycosylated isoform, and band A to nonglycosylated CFTR.
Laboratories Inc., Hercules, California, USA). After washing the columns with 5 volumes $0.5 \mathrm{M} \mathrm{NaCl}$, antibodies were eluted with 4.9 $\mathrm{M} \mathrm{MgCl}_{2}$ for the peptide and $50 \mathrm{mM}$ diethylamine ( $\mathrm{pH} 11.5$ ) for the recombinant CFTR antigen.

MATG1104 and MATG1061 were from Transgène (Strasbourg, France), with CFTR epitopes at amino acid 722-734 and amino acid 503-515 ( $\Delta$ F508), respectively. C24-1 (Genzyme Pharmaceuticals, Cambridge, Massachusetts, USA) recognizes a $\mathrm{COOH}$-terminal CFTR epitope at amino acid 1477-1480. M3A7 was made available by J.R. Riordan (Johnson Research Center, Mayo Clinic Scottsdale, Arizona, USA) and raised against the second CFTR NBF from amino acid 1195-1480. All monoclonal antibodies are affinity purified on protein $\mathrm{G}$ or A. Antibody dilutions refer to stock solutions of $1 \mathrm{mg} / \mathrm{mL}$.

Other antibodies and immunodetection components. Antibodies against alkaline phosphatase, $\boldsymbol{\gamma}$-adaptin, and isotype controls $\left(\operatorname{IgG}_{1 \mathrm{~K}}, \mathrm{IgG}_{2 \mathrm{a}}\right)$ were from Sigma Chemical Co. (St. Louis, Missouri, USA). Antibodies against giantin, $\mathrm{p} 63$, and $\mathrm{Na}^{+} / \mathrm{K}^{+}$ ATPase were a kind gift from H.-P. Hauri (Biozentrum, Basel, Switzerland). Anti-lysozyme was from DAKO Corp. (Hamburg, Germany). Biotin-SP-conjugated goat anti-mouse, goat anti-rabbit $\mathrm{F}\left(\mathrm{ab}^{\prime}\right)_{2} \operatorname{IgG}(\mathrm{H}+\mathrm{L})$, streptavidin/FITC, and streptavidin/Cy3 were from dianova (Hamburg, Germany). Biotinylated alkaline phosphatase and horseradish peroxidase streptavidin complexes, diaminobenzidine tetrahydrochloride (DAB), and New Fuchsin were from DAKO Corp.

Immunobistochemistry. Tissue specimens were cryofixed in liquid nitrogen, embedded in OCT (Miles Inc., Elkhart, Indiana, USA) before taking $5-\mu \mathrm{m}$ cryosections, air dried, and fixed for 5 minutes at $-20^{\circ} \mathrm{C}$ in methanol or for 10 minutes at room temperature in acetone. Alternatively, fixation was carried out in formaldehyde for standard paraffin embedding and analysis of $4-\mu \mathrm{m}$ sections. Immunohistochemical analysis was performed in the different tissues using indirect immunofluorescence (FITC and Cy3) and enzymatic methods with the following optimized CFTR antibody dilutions: M3A7 for immunofluorescence 1:10-1:50, for enzyme-mediated detection in cryosections 1:50-1:200; MATG1104 for immunofluorescence 1:200-1:400, scattered cells in submucosal glands antibody dilution up to $1: 800$, for enzyme-mediated detection in cryosections 1:1,000-1:2,500; MATG1061 for immunofluorescence 1:200-1:400, for enzyme-mediated detection in cryosections 1:300-1:1,000; PAC13 for immunofluorescence 1:200-1:400, for enzymatic detection in paraffin-embedded tissue specimens 1:50; PAC865 for immunofluorescence 1:200; C24-1 for immunofluorescence 1:50-1:100. Indirect immunofluorescence was performed as described previously (23). Enzymatic detection was carried out in the same way, but by using either streptavidin/biotinylated horseradish peroxidase or streptavidin/biotinylated alkaline phosphatase complexes, or the APAAP method. DAB/nickel chloride or New Fuchsin was used as substrate. Endogenous enzyme activities were blocked by a 20 -minute preincubation in $80 \%$ methanol $/ 0.6 \%$ hydrogen peroxide (horseradish peroxidase) or with $0.2 \mathrm{mM} \mathrm{lev-}$ amisole (alkaline phosphatase). Methodical negative controls were performed in parallel for all specific labeling by omitting the primary antibody and replacing it with the isotype control or the preimmune serum, or by peptide competition. For the later, $1 \mu \mathrm{g}$ of CFTR antibody in the dilution used was preincubated for 1 hour at $20^{\circ} \mathrm{C}$ with an excess of CFTR antigen (5 $\mu \mathrm{g})$. CFTR specificity was further demonstrated by the absence of specific signals in internal negative controls (CFTR-negative tissue specimens). Three skin biopsies from patients homozygous for the CFTR stop mutations R553X and G542X and 1 rectal suction biopsy homozygous for an out-of-frame deletion of exons 2 and 3 (biopsy and mutation analysis provided by F. Mekus, Medizinische Hochschule Hannover) that results in a stop in exon 4 were analyzed by CFTR immunohistochemistry 

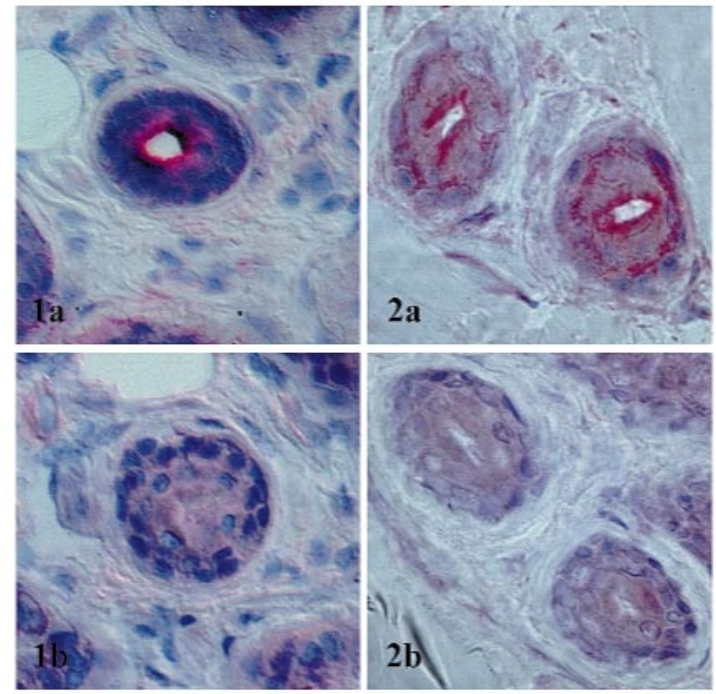

M3A7

cryosection

\section{MATG1104}

cryosection

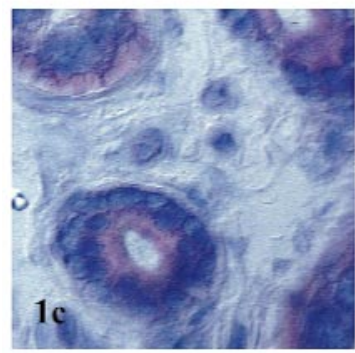

isotype control

cryosection

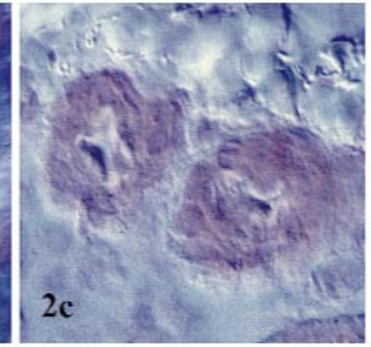

internal control

cryosection

(R553X/ R553X)
PAC13

paraffin section

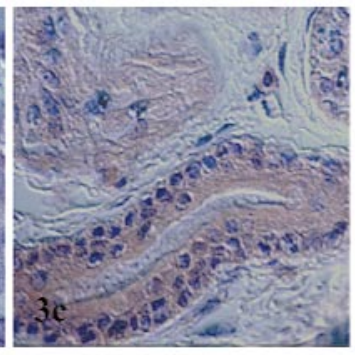

pre-immune serum

paraffin section

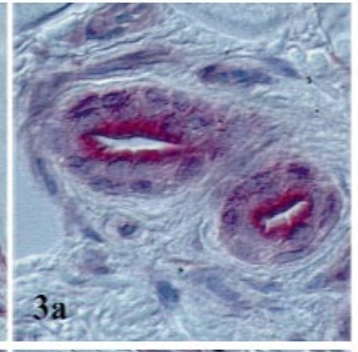

non CF

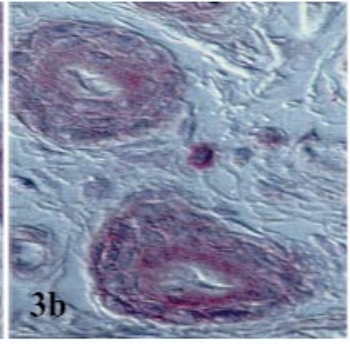

$\Delta \mathrm{F} 508 \mathrm{CF}$

\section{Figure 2}

CFTR expression in sweat glands. Immunohistochemical CFTR labeling in cryosections of skin biopsies with M3A7 (1:200; 1a and 1b) and MATG1104 (1:2,500; 2a and 2b) and in paraffin sections with PAC13 $(1: 50 ; \mathbf{3} \mathbf{a}$ and $\mathbf{3 b})$, and detection with alkaline phosphatase/New Fuchsin. The different antibodies correspondingly demonstrate CFTR expression at the luminal surface of the reabsorptive duct of sweat glands in non- $\mathrm{CF}$, but not $\Delta \mathrm{F} 508$ homozygous, $\mathrm{CF}$ tissue specimens. Absence of the specific immunoreactive signals in different negative controls. (1c) Isotype control: M3A7 was replaced by $\operatorname{lgG}_{1 \kappa} ;(2 c)$ internal negative control: MATG1104 was employed for investigation of skin biopsies from patients with 2 null alleles (R553X/R553X); (3c) preimmune serum: the polyclonal CFTR antibody PAC13 was replaced by the preimmune serum of the same rabbit. $\times 1,453$. and compared with non-CF and $\Delta \mathrm{F} 508$ homozygous $\mathrm{CF}$ tissue specimens. Counterstaining was with Harris hematoxylin (Sigma Chemical Co.), except in horseradish peroxidase /DAB-labeled paraffin sections, which were not additionally stained. The fluorescence-labeled sections were mounted in citifluor antifading solution (Agar Scientific Ltd., Stansted, United Kingdom), the others in DPX (Fluka; Sigma-Aldrich Chemie GmbH, Deisenhofen, Germany), and observed with an Axiophot microscope (Carl Zeiss Optische Systeme, Göttingen, Germany) using epifluorescence and Nomarski differential interference illumination. Immunofluorescence analysis was performed by using the following filters. FITC: BP 450-490 $\mathrm{nm}$, FT $510 \mathrm{~nm}$, LP 515-565 nm; Cy3: BP 510-560 nm, FT 580 $\mathrm{nm}$, LP $590 \mathrm{~nm}$. Fluorescence exposure times for CFTR immunolabeling were in the range of $15-60$ seconds. Specific staining and negative controls were always photographed under identical conditions (filters, microscope magnification, and fluorescence exposure time).

Immunoblotting. For protein preparations, the intestinal mucosa was detached from the submucosa using a scalpel or EDTA (24). The isolated mucosal and T84 cells were broken up by ultrasound. Nasal polyps were homogenized with Ultraturrax. Microsomal vesicle and apical membrane preparations were performed as described by Langridge-Smith (25) in the presence of protease inhibitors (pefabloc, EDTA, EGTA; [Merck KG, Darmstadt, Germany], trypsin inhibitor, leupeptin, aprotinin [Sigma Chemical Co.]). Samples were prepared for electrophoresis by adding concentrated sample buffer; they were then incubated for
10 minutes at $37^{\circ} \mathrm{C}$ and separated by a $6 \%$ SDS-PAGE. After transfer onto nitrocellulose membranes (BA 85; Schleicher \& Schuell GmbH, Dassel, Germany), immunodetection was performed by sequential incubations a,b,c, with $2 \mu \mathrm{g} / \mathrm{ml}$ of the particular primary CFTR antibody (MATG1104, M3A7, PAC13, PAC865) (a), biotinylated anti-mouse or anti-rabbit IgG as secondary antibody (b), and streptavidin-conjugated alkaline phosphatase (c). Finally, the chemiluminescence substrate CDP-star was added which was dephosphorylated according to the instructions of the manufacturer (TROPIX; Boehringer Ingelheim Bioproducts Partnership, Heidelberg, Germany). Chemiluminescence was detected by exposure to x-ray film (Reflection NEF-496, Du Pont de Nemours, Deutschland, Bad Homburg, Germany). Deglycosylations were for 3 hours at $37^{\circ} \mathrm{C}$ in the presence of the protease inhibitors mentioned previously. Specificity of immunolabeling was demonstrated by different negative controls: omission of the primary antibody, peptide competition (preincubation of $1 \mu \mathrm{g}$ antibody with $5 \mu \mathrm{g}$ CFTR immunogen for 1 hour at $20^{\circ} \mathrm{C}$ ), and absence of the specific immunoblot signals in a CFTR-negative human tracheal cell line (demonstrated by RT-PCR) and Chinese hamster ovary (CHO) cells.

\section{Results}

CFTR antibodies. For the investigation of CFTR protein expression in patients' tissues, we selected an antibody panel with epitopes spread over the CFTR protein (Figure 1). Specificity for CFTR immunoblot was shown by the 
Figure 3

CFTR expression in the airways. (a) CFTR immunofluorescent labeling of pseudostratified areas of the surface epithelium of nasal polyps from non-CF (1-3) and $\Delta \mathrm{F} 508$ homozygous CF patients (4-9) with MATG1061 (1a and 1b, 4a and 4b; dilution 1:200), MATG1104 (2a and 2b, 5a and 5b; dilution 1:200), and PAC865 ( $3 a$ and $3 b, 6 a$ and 6 b; dilution 1:200). Bottom row: Specificity is demonstrated by different negative controls. (7a and 7b) Peptide competition: $1 \mu \mathrm{g}$ MATG1061 (1:200) was preincubated with 5 $\mu \mathrm{g}$ of CFTR peptide $503-515, \Delta 508$; (8a and $8 \mathrm{~b}$ ) isotype control: MATG1104 was replaced by 1:200 dilution of $\operatorname{lgG}_{1 \kappa}$; $(9 a$ and $9 b)$ preimmune serum: the protein A affinity-purified polyclonal antibody PAC865 was replaced by the protein A affinity-purified preimmune serum (dilution 1:200) from the same rabbit. "a" panels show Nomarski view of indirect CFTR immunofluorescence in "b" panels. Fluorescence exposure times: left colum $n=15 \mathrm{sec}$; middle column $=15 \mathrm{sec}$; right column $=30 \mathrm{sec} . \times 2,420$. (b) CFTR expression in airway submucosal gland ducts. CFTR immunolabeling was found in scattered cells of the duct of submucosal glands in non-CF (1a and $1 \mathrm{~b}, 2 \mathrm{a}$ and $2 \mathrm{~b}$ ) and $\Delta \mathrm{F} 508$ homozygous CF ( $3 \mathrm{a}$ and $3 \mathrm{~b}, 4 \mathrm{a}$ and $4 \mathrm{~b}$ ) tissue specimens and is demonstrated with CFTR antibodies MATG1104 (1a and $1 \mathrm{~b}, 3 \mathrm{a}$ and $3 \mathrm{~b} ; 1: 200$ ) and M3A7 ( $2 \mathrm{a}$ and $2 \mathrm{~b}, 4 \mathrm{a}$ and $4 b ; 1: 50)$. In $5 a$ and 5 b, anti-CFTR antibody was replaced by nonspecific $\lg \mathrm{G}_{1 \kappa}(1: 50)$. "a" panels show Nomarski view of indirect immunofluorescence in "b" panels. $\times 2,516$. In the insets, the localization of wild-type and $\Delta$ F508 CFTR immunoreactive signals at the apex of epithelial cells is resolved at higher magnification. a
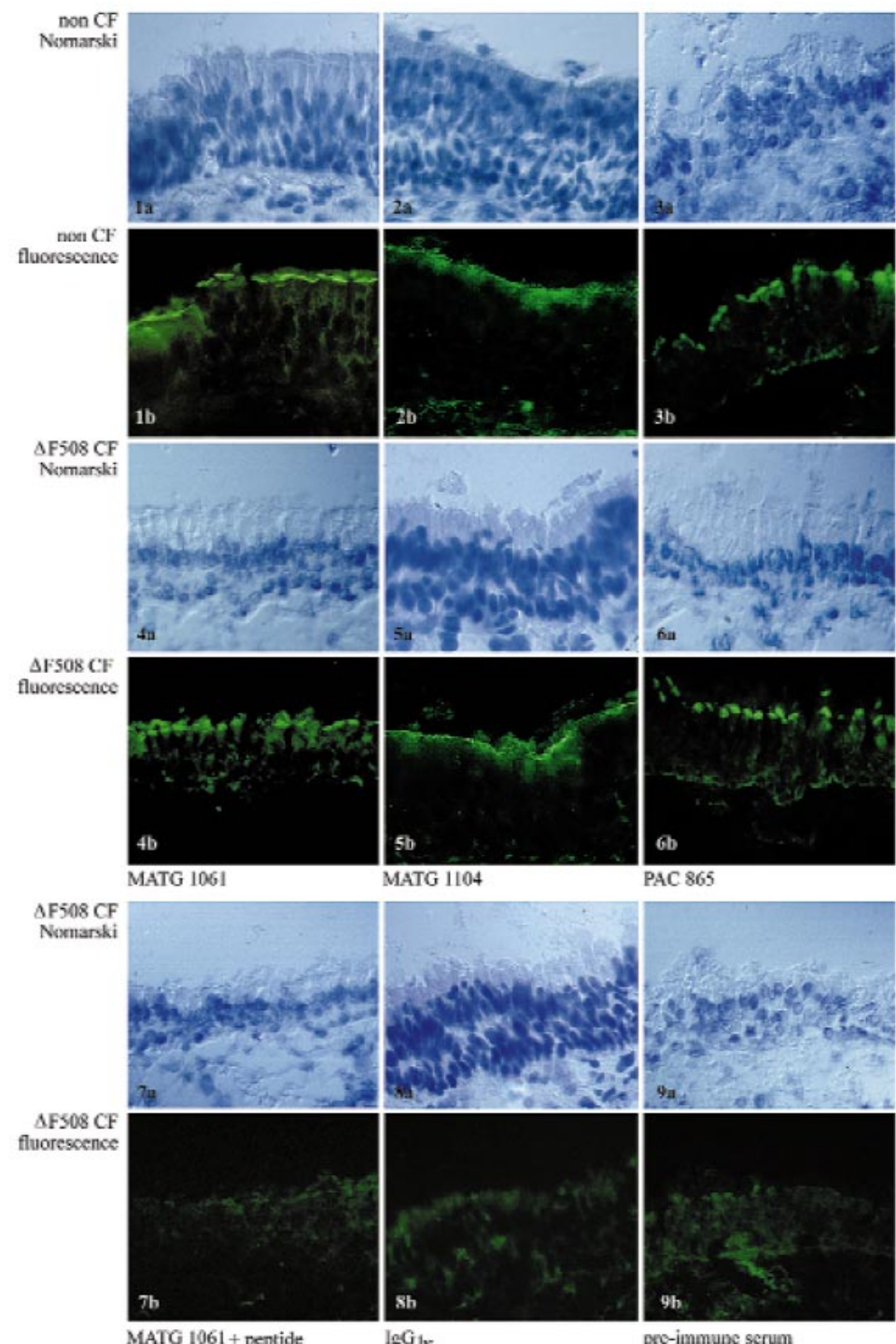

b

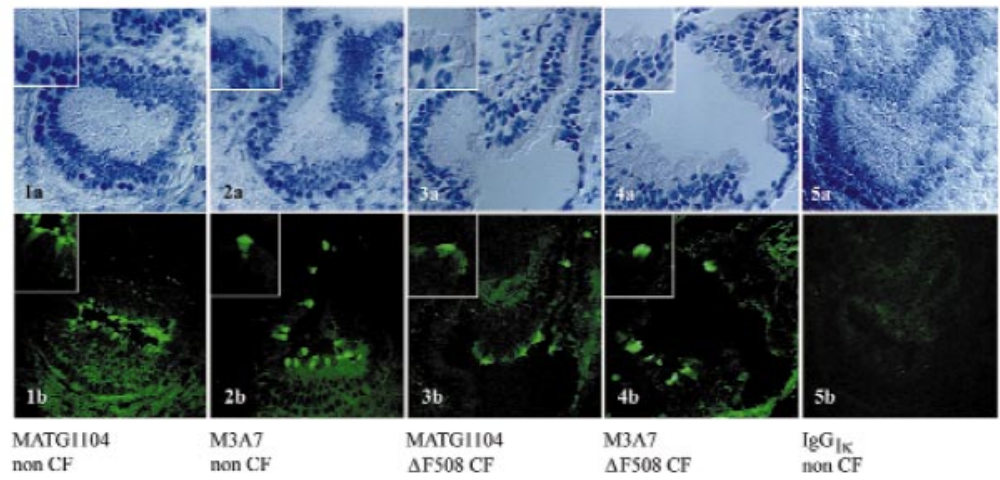

characteristic immunoreactive bands at approximately $190 \mathrm{kDa}$ and $170 \mathrm{kDa}$, which could be discriminated by deglycosylation with $N$-glycosidase F and endoglycosidase $\mathrm{H}$ into mature and core-glycosylated CFTR (see Figure 5). Suitability for immunocytochemistry was demonstrated by the established CFTR expression pattern, characterized by apical immunolabeling of filter-grown T84 cells (26), pseudostratified respiratory epithelia $(23,27)$, the luminal surface of submucosal glands (18), liver bile ducts (28), and reabsorptive ducts of sweat glands $(19,29)$. Specificity of immunoreactive signals was confirmed for all investigated non-CF and CF tissues by the generally accepted negative controls: omission of CFTR antibody, replacement by the preimmune serum or isotype control, or peptide competition. For examples, see Figure 2, Figure 3a (bottom rows), Figure 4d (1a, 1b), and Figure 5c (30). 
a

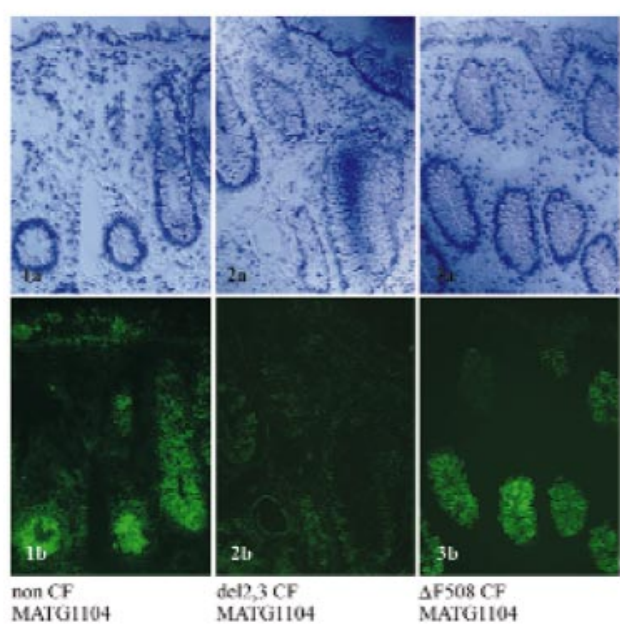

b

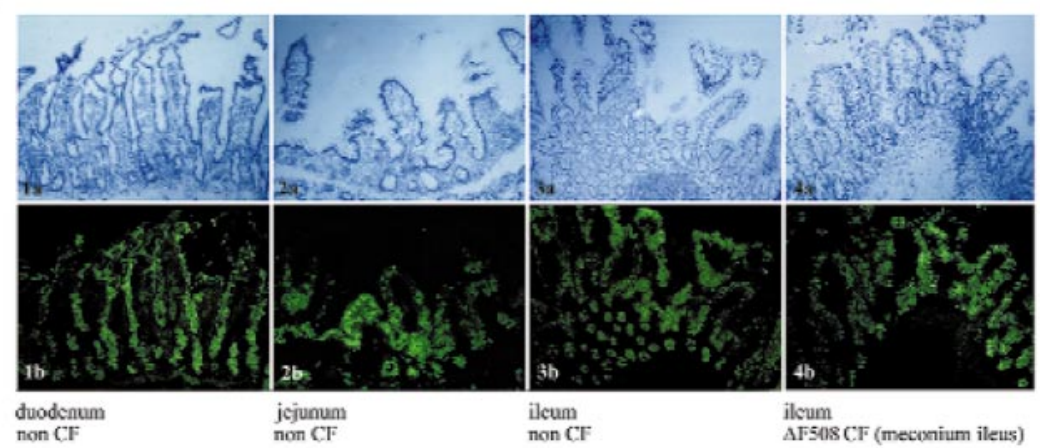

C

\section{Figure 4}

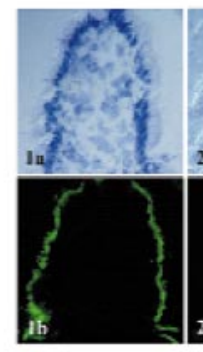

$$
\text { alkaline }
$$
pheephatase
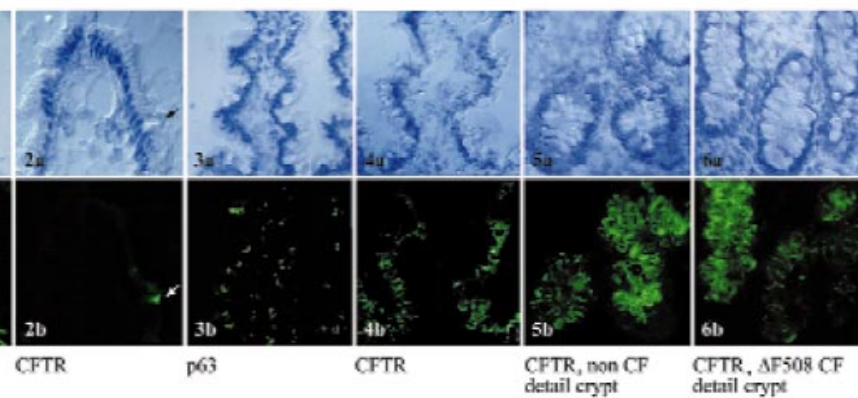

d

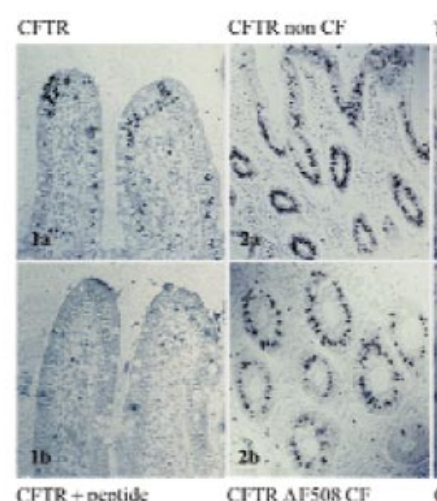

Y-ausptin
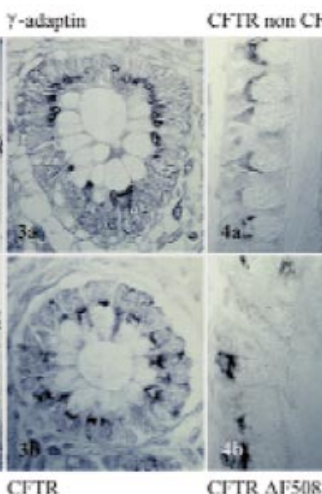

CFTR non CF

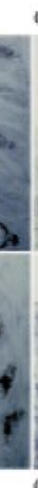

CFIR non $\mathrm{CH}$

CFTR localization in non-CF and $\triangle \mathrm{F} 508 \mathrm{CF}$ tissues (see Table 1)

Eccrine sweat gland. In the sweat gland, CFTR immunoreactivity was found in the apical domain of luminal reabsorptive duct cells of non-CF skin biopsies $(n=5)$, where-
CFression in the intestine, (a) CFTR immunoreactive signals of the intesCFTR antibody MATC1104 (1:200). Fluorescence exposure times for $1 b, 2 b$, and $3 \mathrm{~b}$ were $30 \mathrm{sec}$. "a" panels show Nomarski microscopy of indirect CFTR immunofluorescence in " $b$ " panels. $\times 1,241$. (b) General view of CFTR labeling patterns in duodenum, jejunum, and ileum of adult non-CF intestine (1-3) and newborn PAC865 (1:200). Fluorescence exposure times for duodenum: $15 \mathrm{sec}$; jejunum: s show Nomarski microscopy of indirect CFTR immunofluorescence in " $b$ " panels. $\times 616$. (c) CFTR immunolabeling of the intestine was compared with the signal pattern of marker proteins of different cellular membranes. CFTR expression in isolated intestinal cells of the villi in duodenum and jejunum (2a and 2b, arrow; MATG1104, 1:200) appears apical when compared with a marker of the luminal cell membrane of intestinal villi ( $1 \mathrm{a}$ and $1 \mathrm{~b}$ alkaline phosphatase). Similar immunoreactive labeling patterns of CFTR (4a and 4b; PAC13, $1: 200)$ and a marker protein for the ER ( $3 a$ and $3 \mathrm{~b} ; \mathrm{p} 63$ ) in intermediate crypts of jejunum, labeling of both proteins predominantly within mucussecreting cells. Identical CFTR immunoreactivity in deep crypts of the ileum of non-CF ( $5 a$ and $5 b$; PAC865, 1:200) and $\Delta F 508$ homozygous CF patients (6a and 6b; PAC865, 1:200). Fluorescence exposure times: $1 \mathrm{~b}=20 \mathrm{sec} ; 2 \mathrm{~b}=60 \mathrm{sec} ; 3 \mathrm{~b}$ $=60 \mathrm{sec} ; 4 \mathrm{~b}=30 \mathrm{sec} ; 5 \mathrm{~b}=15 \mathrm{sec} ; 6 \mathrm{~b}=15 \mathrm{sec}$. "a" panels show Nomarski microscopy of indirect CFTR immunofluorescence in " $b$ " panels. $\times 2,467$. (d) CFTR immunolabeling in paraffin-embedded intestinal tissue specimens with PAC13 (1:50) and signal detection with horseradish peroxidase and $\mathrm{DAB} /$ nickel chloride as chromogen substrate. CFTR immunolabeling within intestinal goblet cells (1a) was forced out by peptide competition with CFTR immunogen (CFTR 1468-1480) (1b). Comparison of CFTR immunolabeling of non-CF (2a) and $\Delta F 508$ homozygous CF ileum (2b) in general view. CFTR immunolocalization within goblet cells in a high-magnification view demonstrates that CFTR signals are intracellular (3b) and overlap with the spatial distribution of the trans-Golgi network, as indicated by $\gamma$-adaptin immunolabeling (3a). CFTR labeling within goblet cells is indistinguishable in subcellular localization and intensity in non-CF (4a and 5a) and $\triangle \mathrm{F} 508$ homozygous $\mathrm{CF}$ tissues ( $4 \mathrm{~b}$ and $5 \mathrm{~b}$ ). $1 \mathrm{a}$ 1b, 2a, 2b: $\times 616$. 3a, 3b, 4a, 4b, 5a, 5b: ×6,168. 


\section{Figure 5}

Immunoblot analysis of CFTR expression in nasal polyps and the intestine of non-CF and $\triangle F 508$ homozygous CF patients. Discrimination of CFTR glycoforms by deglycosylation (generation of unglycosylated band $\mathrm{A}$ ) with $\mathrm{N}$-glycosidase $\mathrm{F}$ and endoglycosidase $\mathrm{H}$; the latter reacts with core-glycosylated CFTR (band B) but not with mature CFTR (band C). Deglycosylations were for 3 hours at $37^{\circ} \mathrm{C}$ in the presence of protease inhibitors. (a) The major CFTR immunoreactive bands of non-CF and $\Delta \mathrm{F} 508$ homozygous $\mathrm{CF}$ nasal polyps and intestinal tissue specimens were indistinguishable from complex-glycosylated band C of T84 cells. In the intestine, CFTR expression was highest in membrane preparations from duodenum and decreased in tissue specimens from jejunum and ileum. Immunodetection was performed with MATG1104 (1:500). (b) Complex modification of the major CFTR immunoreactive signal of $\Delta F 508$ homozygous CF intestine (right) is demonstrated by sensitivity to $\mathrm{N}$-glycosidase $\mathrm{F}$ and resistance to endoglycosidase $\mathrm{H}$, as is the case for mature CFTR of control non-CF intestine (middle) and T84 cells (left). Immunodetection with M3A7 (1:500). (c) Specificity of the immunoreactive bands from intestinal tissue specimens for CFTR is demonstrated by the characteristic mobility shifts in deglycosylation assays with $\mathrm{N}$ glycosidase $\mathrm{F}$ and endoglycosidase $\mathrm{H}$ and by peptide competition for antibody binding with the CFTR immunogen. (1) From adult non-CF duodenum; (2) from jejunum of the same patient; (3) from adult ileum of a $\Delta \mathrm{F} 508$ homozygous CF patient. "a" lanes show deglycosylation of the membrane preparations with $\mathrm{N}$-glycosidase F. "b" lanes show peptide competition with the CFTR immunogen $(1 \mu \mathrm{g}$ MATG1104 preincubated at $20^{\circ} \mathrm{C}$ with 5 $\mu \mathrm{g}$ CFTR peptide 722-734). Immunodetection with MATG1104 (1:500). a

\section{N-glycosidase F $-\quad-\quad+\quad-\quad+\quad-\quad-\quad-\quad+\quad+\quad-$}

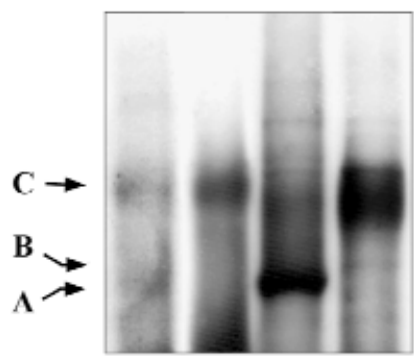

wt $\Delta$ F508

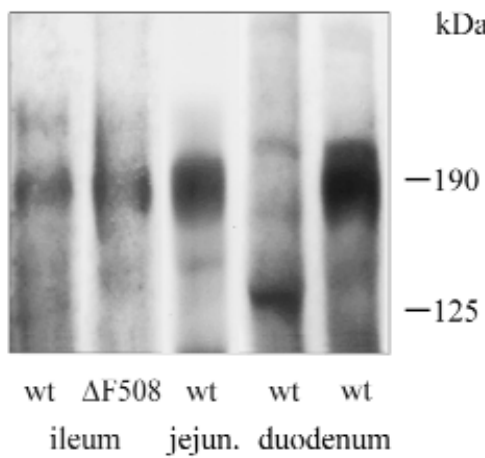

b

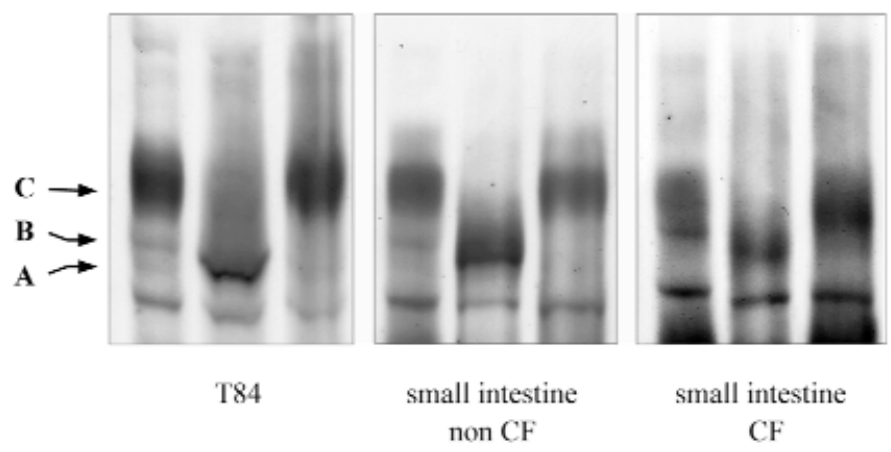

C ing was demonstrated by common negative controls and the absence of specific signals in skin biopsies homozygous for the stop mutations G542X and R553X $(n=3)$.

Airways. CFTR expression was investigated in the epithelium of nasal polyps, which reflects the morphology and CFTR expression pattern of the upper and lower airways' surface epithelium (Figure 3a). Immunolabeling of wild-type $(n=8)$ and $\Delta$ F508 CFTR $(n=10)$ was compared in areas of pseudostratified respiratory epithelium, because dedifferentiation to a hyperplasia or metaplasia was associated with an intracellular localization or absence of CFTR protein (27).

In nasal polyps, CFTR expression was found in the apical domain of ciliated cells and could be confirmed by enrichment of the protein in apical vesicle preparations. CFTR immunoreactivity and signal intensity were indis- tinguishable in non-CF and $\Delta \mathrm{F} 508$ homozygous $\mathrm{CF}$ nasal polyps. CFTR immunolocalization in the nasal epithelium of a $\Delta$ F508 homozygous patient appeared highly similar to the labeling pattern of an apical marker protein, the alkaline phosphatase, but completely differed from the signal pattern of the ER resident protein $\mathrm{p} 63$.

Variations in method, such as the alternative immunolabeling with green or red fluorophores (FITC and Cy3) or immunodetection with enzyme-mediated chromogen labeling, had no influence on the staining pattern.

Submucosal glands. In submucosal glands of nasal polyps and bronchi, we found an apical CFTR immunolabeling in the duct and acini of the glands, where signals were detected in lysozyme-positive serous cells (Figure $3 \mathrm{~b}$ ). In addition to this surface labeling, we detected an intensive CFTR immunoreactivity in scattered cells of the gland duct. 
These strongly CFTR-positive cells had been described previously at the CFTR mRNA and protein level (18).

The analysis of CFTR expression in submucosal glands from $\Delta F 508$ homozygous patients led to the reliable detection of the mutant protein in the apex of these scattered cells of the gland duct using the CFTR antibodies M3A7 and MATG1104. CFTR labeling on the surface of the $\Delta$ F508 homozygous gland acini was found in only 2 out of 4 tissue specimens (C24-1, MATG1104). In a single acinus of these glands, we found a similar apical CFTR immunoreactivity with M3A7. In the other $\Delta \mathrm{F} 508$ homozygous tissue specimens, CFTR immunolabeling in the submucosal glands appeared very weak or absent. In non-CF patients $(n$ $=4$ ), clear CFTR signals were found in the acini of 2 specimens, while CFTR expression of the other glands was very low. In the non-CF and $\Delta \mathrm{F} 508$ homozygous $\mathrm{CF}$ tissue specimens where we could detect CFTR expression, immunoreactive signals were indistinguishable.

The CFTR expression patterns of submucosal glands are in agreement with the findings of Engelhardt et al. (18), although in Engelhardt's study mutant CFTR was not detectable in the 4 analyzed $\Delta \mathrm{F} 508$ homozygous lung explants. The unequal detection rates of $\Delta$ F508 CFTR immunoreactive signals could reflect the limited number of specimens investigated in both studies and/or the influence of dedifferentiation (27) on CFTR expression, indicating the need for a sufficiently large panel for the analysis of the inherently variable tissue specimens.

Intestine. Immunoreactive CFTR signals could be detected in intestinal goblet cells irrespective of the section of the intestine (from duodenum to rectum) or the age of the patient (Figure 4). The intensity of immunoreactivity was most prominent in duodenum and decreased in the more distal intestine. CFTR localization within the cell was compared with cellular marker proteins. The apical and basolateral cell membranes, the ER, the Golgi complex, and the trans-Golgi network were labeled with antibodies against alkaline phosphatase, $\mathrm{Na}^{+} / \mathrm{K}^{+}$-ATPase, $\mathrm{p} 63$, giantin, and $\gamma$-adaptin, respectively. The CFTR signal pattern was similar to the immunoreactive tracings of the ER, Golgi complex, and the trans-Golgi network, suggesting an intracellular CFTR expression along the secretory compartments of intestinal goblet cells. The investigation of CFTR localization in the more conserved morphology of paraffinembedded tissue sections revealed an extension of CFTR immunoreactivity from the basal pole of the cell to the region of the early secretory vesicles but excluded the nucleus and the mucus-filled granules of the goblet cell. The comparison of wild-type $(n=11)$ and $\Delta$ F508 CFTR expression $(n=8)$ demonstrated an identical cellular distribution in the investigated intestinal sections. Non-CF and CF signal intensities and intracellular localization could not be differentiated by enzymatic or immunofluorescence analysis.

Besides the intracellular CFTR labeling in mucussecreting cells, an apical CFTR immunoreactivity was found in scattered enterocyte-like cells of the villi in tissue specimens from the duodenum and jejunum, which were only accessible from non-CF patients. These immunoreactive CFTR signals could be ascribed to an already known CFTR-positive, but otherwise ill-defined, cell type that differs from nutrient-absorbing enterocytes and other characterized intestinal cell populations (31).

Specificity of the immunoreactive signals in the intestine was demonstrated by the common negative controls and the absence of the specific labeling pattern in a rectal biopsy from a CF patient homozygous for an out-of-frame deletion of exons 2 and 3 , in contrast to CFTR labeling of the crypts in the corresponding tissue specimens of non$\mathrm{CF}$ and $\triangle \mathrm{F} 508$ homozygous CF patients (Figure 4a).

CFTR immunoblot analysis in non-CF and $\triangle F 508$ CF nasal polyps and intestine. CFTR expression was investigated by immunoblot in microsomal membrane preparations from non-CF $(n=20)$ and $\Delta$ F508 homozygous CF $(n=$ 12) nasal polyps and intestinal mucosa cells (non-CF: $n$ $=7 ; \Delta$ F508/ $\Delta$ F508: $n=3$ ) (Figure 5). A diffuse immunoreactive band of approximately $190 \mathrm{kDa}$ corresponded with mature CFTR, and a sharp band with slightly enhanced electrophoretic mobility related to the core-glycosylated protein of T84 cells, both of which were absent in all negative controls. The limited amount of protein in sweat gland preparations of a skin biopsy did not permit the detection of CFTR. As expected from our RT-PCR data (23), CFTR protein expression was low in nasal polyps and could only be shown by

Table 1

Immunohistochemical analysis of CFTR expression in various non-CF and $\Delta F 508$ homozygous CF tissues with different CFTR antibodies

\begin{tabular}{|c|c|c|c|c|c|c|c|c|c|c|c|c|}
\hline \multirow{4}{*}{$\begin{array}{l}\text { Organ } \\
\text { Tissue } \\
\text { Item }\end{array}$} & \multicolumn{6}{|c|}{ Airways } & \multirow{2}{*}{\multicolumn{4}{|c|}{$\begin{array}{l}\text { Intestine } \\
\text { Mucosa }\end{array}$}} & \multicolumn{2}{|c|}{ Sweat glands } \\
\hline & \multirow{2}{*}{\multicolumn{2}{|c|}{$\begin{array}{c}\begin{array}{c}\text { Respiratory } \\
\text { epithelium }\end{array} \\
\text { Pseudostratified } \\
\text { epithelium }\end{array}$}} & \multicolumn{4}{|c|}{$\begin{array}{l}\text { Submucosal } \\
\text { glands }\end{array}$} & & & & & \multirow{2}{*}{\multicolumn{2}{|c|}{$\begin{array}{l}\text { Reabsorptive } \\
\text { duct }\end{array}$}} \\
\hline & & & \multicolumn{2}{|c|}{$\begin{array}{l}\text { Duct, } \\
\text { isolated cells }\end{array}$} & \multicolumn{2}{|c|}{$\begin{array}{l}\text { Serous } \\
\text { acini }\end{array}$} & \multicolumn{2}{|c|}{$\begin{array}{l}\text { Goblet } \\
\text { cells }\end{array}$} & \multicolumn{2}{|c|}{$\begin{array}{l}\text { Isolated cells, villi, } \\
\text { proximal intestine }\end{array}$} & & \\
\hline & $\begin{array}{c}\text { Non-CF } \\
n=8\end{array}$ & $\begin{array}{l}\Delta \mathrm{F} 508 \\
n=10\end{array}$ & $\begin{array}{c}\text { non-CF } \\
n=1\end{array}$ & $\begin{array}{c}\Delta \mathrm{F} 508 \\
n=1\end{array}$ & $\begin{array}{c}\text { non-CF } \\
n=4^{\mathrm{A}}\end{array}$ & $\begin{array}{c}\Delta \mathrm{F} 508 \\
n=4^{\mathrm{A}}\end{array}$ & $\begin{array}{c}\text { non-CF } \\
n=11\end{array}$ & $\begin{array}{c}\Delta \mathrm{F} 508 \\
n=8\end{array}$ & $\begin{array}{c}\text { non-CF } \\
n=2\end{array}$ & $\begin{array}{c}\Delta \mathrm{F} 508 \\
n=0\end{array}$ & $\begin{array}{c}\text { non-CF } \\
n=5\end{array}$ & $\begin{array}{c}\Delta \mathrm{F} 508 \\
n=4\end{array}$ \\
\hline MATG1104 & + & + & + & + & + & + & + & + & + & NA & + & - \\
\hline MATG1061 & + & + & ND & ND & ND & ND & + & + & + & NA & ND & ND \\
\hline PAC13 & + & + & ND & ND & ND & ND & + & + & + & NA & + & - \\
\hline PAC865 & + & + & ND & ND & ND & ND & + & + & + & NA & ND & ND \\
\hline C24-1 & + & + & ND & ND & + & + & ND & ND & ND & NA & ND & ND \\
\hline M3A7 & - & $-/ \pm$ & + & + & - & $-/ \pm$ & - & - & + & NA & + & - \\
\hline
\end{tabular}

CFTR signals were: + , detectable; $-/ \pm$, undetectable, positive labeling in only a few cells of a single specimen; -, not detectable in all investigated tissue specimens; ND,

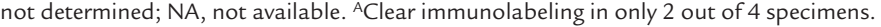


immunoblot in a subportion of the investigated specimens. In preparations of the proximal intestine, CFTR detection was reliable, confirming the enhanced CFTR expression seen in immunohistochemistry. Intensity of CFTR immunoblot signals from the duodenum was comparable to identically processed protein preparations of T84 cells but declined in jejunum and ileum. This gradient of CFTR expression was confirmed by our immunohistochemical data and had been previously described at the transcript level (32). Tissue specimens from CF patients were taken in the course of the treatment of meconium ileus, or the equivalent in the adult, and originated from distal ileum or proximal colon. The low CFTR expression in this intestinal section causes the CFTR immunoblot signals to be relatively faint.

Analysis of the glycosylation pattern of the main immunoreactive CFTR signal by $N$-glycosidase F and endoglycosidase $\mathrm{H}$ digestions revealed sensitivity to the first enzyme and resistance to the second enzyme, demonstrating the complex modification of mature CFTR. This CFTR glycoform was detected in non-CF and $\Delta \mathrm{F} 508$ homozygous $\mathrm{CF}$ respiratory and intestinal preparations. CFTR immunoreactive signals were indistinguishable in non-CF and $\Delta \mathrm{F} 508$ homozygous nasal polyps. We did not observe a reduction of mature band $\mathrm{C}$ or a predominance of immature band B CFTR in $\Delta$ F508 homozygous nasal polyps. However, in some CFTR immunoblots of tissue specimens from $\Delta \mathrm{F} 508$ homozygous intestine, the mature CFTR immunoreactive band $\mathrm{C}$, but not the immature band $\mathrm{B}$, appeared decreased in comparison with non-CF controls, which may be indicative of a reduced $\Delta \mathrm{F} 508 \mathrm{CFTR}$ protein processing efficiency in the intestine. The detection of complex-glycosylated band C CFTR demonstrates that in respiratory and intestinal tissue specimens a considerable amount of wild-type and $\Delta F 508$ CFTR protein was modified by Golgi glycosidases and hence had escaped the quality control of the ER. The proof of mature CFTR in non-CF and $\Delta \mathrm{F} 508$ homozygous CF tissue specimens contrasts with data from recombinant expression systems, where all $\Delta$ F508 CFTR was retained as core-glycosylated, transport-incompetent protein in the ER, where it was rapidly degraded $(2,6,14)$.

In this study, $\Delta \mathrm{F} 508$ homozygous $\mathrm{CF}$ and non-CF preparations differed in deglycosylation assays. These more often resulted in the loss of immunoreactive CFTR in CF specimens than in non-CF specimens, as a consequence of complete removal of the glycan moiety with $\mathrm{N}$ glycosidase $\mathrm{F}$ but not with the inefficient $O$-glycosidase, suggesting a protease hypersensitivity of mature, glycanfree mutant protein. A similar phenomenon has recently been demonstrated for the immature $\Delta$ F508 CFTR precursor conformation (4).

\section{Discussion}

Immunolocalization of CFTR. Immunodetection of CFTR on the luminal surface of pseudostratified respiratory epithelia, submucosal glands, and reabsorptive sweat ducts corresponds with previous findings $(19,27,29$, $33)$; it fits in with the role of CFTR for chloride and fluid secretion on the surface of the larger airways and submucosal glands and reabsorption of salt from primary isotonic sweat. The expression of CFTR in isolated cells of the villi in the proximal intestine and ducts of submucosal glands was also detected by others. However, the function of these isolated CFTR-expressing cells, which could be of particular interest for CF pathophysiology, is still unclear $(18,31)$.

In contrast to these generally confirmed CFTR expression patterns, the detection of CFTR immunoreactive signals in intracellular compartments of intestinal goblet cells was quite unexpected, because the reduced chloride and fluid secretion in CF gut (34), as well as apical CFTR immunolabeling in colon-derived T84 cells (26), suggested the exclusive localization of the chloride channel on the luminal surface of intestinal crypts. The analysis of CFTR expression in the conserved morphology of paraffin-embedded intestinal tissues with the antibody PAC13 permitted the identification of an additional CFTR-expressing cell type, in accordance with studies on CFTR localization in the guts of mice and piglets (35) and in the human duodenum (36). In cryosections, immunocytochemical analysis of mucus-secreting cells is limited by the relatively poor preservation of this cell type during fixation. Expression of CFTR within membranes of the secretory compartments and endosomes had been previously demonstrated $(37,38)$. However, to our knowledge, predominant intracellular CFTR immunoreactivity is described here for the first time and may reflect a peculiar feature of goblet cells. Condensation of secretory compartments in the scarce cytoplasm is associated with a high density of membranous epitopes that also leads to prevailing immunoreactive signals of the ER resident proteins calnexin and p63 within this cell type (Figure 4c).

CFTR in intracellular compartments of goblet cells could function on the biosynthetic pathway (39) in constitutive membrane trafficking (40) and in coupling secretion of mucus, water, and salt $(41,42)$. A role for CFTR in CAMP- and chloride-dependent exocytosis and endocytosis was demonstrated for the wild-type, but not for a defective, chloride channel (43) and may be attributed to an association of the vesicle fusion process with electrolyte transport (44). A combined secretion of mucus and chloride upon CFTR stimulation was demonstrated in subepidermal glands of Xenopus laevis by Engelhardt et al. (41) and by studies on submandibular (45), pancreatic epithelial (42), gallbladder (46), and submucosal glands (47), which suggested a role for CFTR in mucus release. Alterations in the glycan composition of CF mucins may result from defective CFTR expression in mucus cells (39).

The inability to detect CFTR expression on the surface of fluid-secreting crypts may be explained by a low density of chloride channels in this location. In cryosections, the strong immunofluorescence signals of goblet cells that are closely packed within the crypts would cover a faint apical labeling of crypt enterocytes, while the sensitivity in formaldehyde-fixed paraffin-embedded tissues may be too low for detection of slight epitope concentrations.

The immunohistochemical labeling of CFTR protein expression is consistent with the in situ hybridization pattern of CFTR mRNA transcript in the gastrointesti- 
nal tract. Both protein and mRNA decreased from proximal to distal intestine and were concentrated in the crypts and in scattered cells of the villi in the duodenum and jejunum. The homogeneous distribution of CFTR transcript within the crypts and localization of the CFTR chloride channel in fluid and mucussecreting HT29 cells $(48,49)$ suggested various CFTRpositive intestinal cell types. The identification of CFTR expression in goblet cells, besides the expression in fluid-secreting enterocytes, convincingly explains intestinal obstruction syndromes by underhydrated secretions and altered mucus in CF patients.

Variability of $\triangle F 508$ CFTR expression in CF-affected tissues. The investigation by immunohistochemistry and immunoblot of CFTR in tissues of the intestinal and respiratory tracts and sweat glands of CF-affected patients revealed a tissue-specific variability of the impact of the $\Delta$ F508 mutation on CFTR protein expression. Although $\Delta$ F508 CFTR was undetectable in sweat glands by immunohistochemistry, expression could not be differentiated from the wild-type in intestinal and respiratory epithelia by either signal intensity or cellular localization and was consistent with $\Delta \mathrm{F} 508 \mathrm{CFTR}$ in the area of the target membrane. While the apical CFTR labeling in pseudostratified respiratory epithelia and submucosal glands suggests the maturation of both wild-type and $\Delta$ F508 CFTR protein, the intracellular CFTR immunolocalization within intestinal goblet cells gives no information on CFTR protein processing. Maturation of $\triangle$ F508 CFTR in respiratory and intestinal tissues was demonstrated by immunoblot analysis, where the acquisition of endoglycosidase $\mathrm{H}$ resistance confirmed processing of $\triangle F 508$ CFTR beyond the ER.

A variable degree of $\Delta F 508$ CFTR expression and maturation was also seen in different heterologous expression systems, ranging from a complete absence of fully processed CFTR in overexpressing vaccinia virus transfectants (50), a maturation efficiency of approximately $20-50 \%$ of the wild-type but immature mutant CFTR in $\mathrm{CHO}$ and baby hamster kidney (BHK) cells (14), to low levels of fully processed $\Delta$ F508 CFTR in mouse mammary epithelial cells (15), of which the latter more closely simulates the endogenous situation. The dependence of $\Delta$ F508 CFTR maturation and targeting upon epithelial polarization has recently been demonstrated in stably transfected cells, as well as in endogenous CFTR-expressing epithelial cells $(51,52)$.

The susceptibility of CFTR toward the expression background is also demonstrated by the variable phenotypes of $\Delta F 508$ CF mouse models, which exhibit prominent differences in cftr transcript and protein expression (53-55), resulting either in a CF phenotype that corresponds to a null mutation $(53,54)$ or in some residual chloride channel activity (55), although even in the latter case immature band B cftr was the major form, and the immunocytochemical cftr signal in intestinal epithelium was low (55). According to this data, the processing of $\Delta \mathrm{F} 508$ mutants in vivo seems to be more impaired in mice than in humans, although the low sensitivity and specificity of the available anti-murine $\mathrm{cftr}$ antibodies that so far have prevented any comprehensive protein expression analysis in CF mice preclude any definitive statement at this time.
Tissue specificity of CFTR expression is well documented by the amounts of CFTR mRNA transcript in different epithelia (56), the specific usage of transcription start sites (57), and the expression of splice variants (58). On the CFTR protein level, a recent investigation suggested that not only agonist-stimulated CFTR trafficking but also CFTR endocytosis and membrane recycling are cell type-specific (59), while for other proteins, cell specificity was also demonstrated for protein folding (60). In heterologous expression systems, decreased or abrogated $\Delta$ F508 CFTR protein expression resulted from impaired folding and premature degradation of the protein (14). Posttranslational events such as the efficiency of the folding or quality control machineries, the half-life of the protein, or cell type-specific protein targeting could likewise lead to the detected differences of mutant CFTR expression in sweat glands and the respiratory and intestinal tracts, demonstrating the influence of cell type-specific factors on the disease phenotype, a phenomenon that was also observed in other disorders (61).

The tissue-specific expression of $\Delta F 508$ CFTR in CF patients may explain why some epithelia are more prone to manifestations of CF. Sweat glands, where $\Delta$ F508 CFTR expression was more dramatically affected than in respiratory and intestinal epithelia, also display the most consistent CF phenotype. Elevated sweat chloride concentrations are the first indication of $\mathrm{CF}$ and can be found even in the absence of other CF symptoms (62), whereas in the respiratory and intestinal tracts, $\Delta \mathrm{F} 508$ CF disease is variable.

Implications for understanding $\triangle F 508 \mathrm{CF}$ disease. This study demonstrates that $\triangle F 508$ CFTR protein is not absent in all CF patients' tissues, as suggested by defective maturation and premature degradation of the mutant in heterologous expression systems. Instead, expression was found to be tissue specific and ranged from null to apparently normal amounts in the respiratory and intestinal tracts of CF patients, demonstrating that factors can enhance CFTR processing in the patient. However, the presence of $\Delta$ F508 CFTR protein in these tissues does not neutralize the basic defect in $\Delta \mathrm{F} 508$ homozygous patients, as demonstrated by the elevated nasal potential (63) and aberrant ion flow in rectal biopsies (64).

This inconsistency could be explained by an ultrastructural mislocalization of the mutant protein in a vesicle compartment beneath, but not in, the plasma membrane, although stimulation of the mutant chloride channel in vivo suggests expression of at least some $\Delta$ F508 CFTR on the cell surface (65). The localization of most $\Delta \mathrm{F} 508$ CFTR in a nearby vesicle compartment $(38,66)$ cannot be excluded by the immunohistochemical data and would be consistent with a role of CFTR in membrane recycling (67-69) and the increase of mutant cell surface chloride channels after stimulation of vesicle trafficking in $\Delta$ F508 homozygous respiratory epithelial cells (70).

However, a reduction of cell surface chloride channels alone hardly explains the CF phenotype, because low levels of full-length CFTR transcript (71) and protein (72-74) are sufficient to offer protection from symptoms of CF lung and intestinal disease, suggesting that wild-type and $\Delta F 508$ CFTR cannot be assumed to be equivalent. Alterations in the transport and/or regulatory features of 
$\Delta$ F508 CFTR may contribute to the disease phenotype. The demonstration that normally processed $\Delta \mathrm{F} 508$ CFTR protein is present in some CF-affected tissues suggests that the ER quality control barrier is not the only determinant of $\Delta \mathrm{F} 508 \mathrm{CF}$ disease. Pharmacologic attempts to activate the defective protein that passed this bottleneck of CFTR expression in the affected tissues should be of therapeutic benefit for the treatment of CF lung and intestinal disease.

\section{Acknowledgments}

We thank the CF patients, their parents, and attending physicians for their participation; Transgène, J.R. Riordan, and H.-P. Hauri for providing antibodies; H.-J. Rothkötter, J. Westermann, and S. Grieshop for technical support; J. Hinnrasky for immunolabeling of bronchial tissue specimens; and J. Clemens and $U$. Wulbrand for the supply of the recombinant CFTR-NBF fusion protein. We gratefully acknowledge U. Hofmann, D. Booß, W. Mothes, H. Ostertag, H.J. Maschek, G. Wittstock, A.M. Holschneider, M. Ballmann, and their teams for the supply of specimens; T. Schößler and H. Bolte for technical assistance of sweat gland analysis; and J. Zeyßig for reading the manuscript. This work was supported by the Deutsche Forschungsgemeinschaft and the Christiane Herzog Stiftung.

1. Welsh, M.J., Tsui, L.-C., Boat, T.F., and Beaudet, A.L. 1995. Cystic fibrosis. In The metabolic and molecular bases of inherited disease. 7th edition. C.R.Scriver, A.L. Beaudet, W.S. Sly, and D. Valle, editors. McGraw-Hill. New York, NY. 3799-3876.

2. Cheng, S.H., et al. 1990. Defective intracellular transport and processing of CFTR is the molecular basis of most cystic fibrosis. Cell. 63:827-834.

3. Gregory, R.J., et al. 1991. Maturation and function of cystic fibrosis transmembrane conductance regulator variants bearing mutations in putative nucleotide-binding domains 1 and 2. Mol. Cell. Biol. 11:3886-3893.

4. Zhang, F., Kartner, N., and Lukacs, G.L. 1998. Limited proteolysis as a probe for arrested conformational maturation of $\Delta$ F508 CFTR. Nat. Struct. Biol. 5:180-183.

5. Pind, S., Riordan, J.R., and Williams, D.B. 1994. Participation of the endoplasmic reticulum chaperone calnexin (p88, IP90) in the biogenesis of the cystic fibrosis transmembrane conductance regulator. J. Biol. Chem. 269:12784-12788.

6. Yang, Y., Janich, S., Cohn, J.A., and Wilson, J.M. 1993. The common variant of cystic fibrosis transmembrane conductance regulator is recognized by hsp70 and degraded in a pre-Golgi nonlysosomal compartment. Proc. Natl. Acad. Sci. USA. 90:9480-9483.

7. Sato, S., Ward, C.L., and Kopito, R.R. 1998. Cotranslational ubiquitination of cystic fibrosis transmembrane conductance regulator in vitro. $J$. Biol. Chem. 273:7189-7192.

8. Ward, C.L., Omura, S., and Kopito, R.R. 1995. Degradation of CFTR by the ubiquitin-proteasome pathway. Cell. 83:121-127.

9. Jensen, T.J., et al. 1995. Multiple proteolytic systems, including the proteasome, contribute to CFTR processing. Cell. 83:129-135.

10. Denning, G.M., et al. 1992. Processing of mutant cystic fibrosis transmembrane conductance regulator is temperature-sensitive. Nature. 358:761-764

11. Sato, S., Ward, C.L., Krouse, M.E., Wine, J.J., and Kopito, R.R. 1996. Glycerol reverses the misfolding phenotype of the most common cystic fibrosis mutation. J. Biol. Chem. 271:635-638.

12. Brown, C.R., Hong-Brown, L.Q., Biwersi, J., Verkman, A., and Welsh, W. 1996. Chemical chaperones correct the mutant phenotype of the $\Delta \mathrm{F} 508$ cystic fibrosis transmembrane conductance regulator protein. Cell Stress Chaperones. 1:117-125

13. Lukacs, G.L., et al. 1993. The $\Delta$ F508 mutation decreases the stability of cystic fibrosis transmembrane conductance regulator in the plasma membrane. J. Biol. Chem. 268:21592-21598.

14. Lukacs, G.L., et al. 1994. Conformational maturation of CFTR but not its mutant counterpart $(\Delta \mathrm{F} 508)$ occurs in the endoplasmic reticulum and requires ATP. EMBO J. 13:6076-6086.

15. Haws, C.M., et al. 1996. $\Delta$ F508 CFTR channels: kinetics, activation by forskolin, and potentiation by xanthines. Am. J. Physiol. 270:C1544-C1555.

16. Dalemans, W., et al. 1991. Altered chloride ion channel kinetics associated with the $\Delta$ F508 cystic fibrosis mutation. Nature. 354:526-528.

17. Drumm, M.L., et al. 1991. Chloride conductance expressed by $\Delta$ F508 and other mutant CFTRs in Xenopus oocytes. Science. 254:1797-1799.
18. Engelhardt, J.F., et al. 1992. Submucosal glands are the predominant site of CFTR expression in the human bronchus. Nat. Genet. 2:240-247.

19. Kartner, N., Augustinas, O., Jensen, T.J., Naismith, A.L., and Riordan, J.R. 1992. Mislocalization of $\Delta F 508$ CFTR in cystic fibrosis sweat gland. Nat. Genet. 1:321-327.

20. Rommens, J., et al. 1990. Rapid nonradioactive detection of the major cystic fibrosis mutation. Am. J. Hum. Genet. 46:395-396.

21. Marino, C.R., Matovcik, L.M., Gorelick, F.S., and Cohn, J.A. 1991. Localization of the cystic fibrosis transmembrane conductance regulator in pancreas. J. Clin. Invest. 88:712-716.

22. Annereau, J.-P., et al. 1997. A novel model for the first nucleotide binding domain of the cystic fibrosis transmembrane conductance regulator. FEBS Lett. 407:303-308.

23. Dupuit, F., et al. 1995. CFTR and differentiation markers expression in non-CF and $\Delta$ F508 homozygous CF nasal epithelium. J. Clin. Invest. 96:1601-1611.

24. Bjerknes, M., and Cheng, H. 1981. Methods for the isolation of intact epithelium from the mouse intestine. Anat. Rec. 199:565-574.

25. Langridge-Smith, J.E., Field, M., and Dubinsky, W.P. 1983. Isolation of transporting plasma membrane vesicles from bovine tracheal epithelium. Biochim. Biophys. Acta. 731:318-328.

26. Denning, G.M., Ostedgaard, L.S., Cheng, S.H., Smith, A.E., and Welsh, M.J. 1992. Localization of cystic fibrosis transmembrane conductance regulator in chloride secretory epithelia. J. Clin. Invest. 89:339-349.

27. Brézillon, S., et al. 1995. Decreased expression of CFTR protein in remodeled human nasal epithelium from non-cystic fibrosis patients. Lab. Invest. 72:191-200.

28. Cohn, J.A., et al. 1993. Localization of the cystic fibrosis transmembrane conductance regulator in human bile duct epithelial cells. Gastroenterology. 105:1857-1864.

29. Cohn, J.A., Melhus, O., Page, L.J., Dittrich, K.L., and Vigna, S.R. 1991. CFTR: development of high-affinity antibodies and localization in sweat gland. Biochem. Biophys. Res. Commun. 181:36-43.

30. Kartner, N., and Riordan, J.R. 1998. Characterization of polyclonal and monoclonal antibodies to cystic fibrosis transmembrane conductance regulator. Methods Enzymol. 292:629-652.

31. Ameen, N.A., Ardito, T., Kashgarian, M., and Marino, C.R. 1995. A unique subset of rat and human intestinal villus cells express the cystic fibrosis transmembrane conductance regulator. Gastroenterology. 108:1016-1023.

32. Strong, T.V., Boehm, K., and Collins, F.S. 1994. Localization of cystic fibrosis transmembrane conductance regulator mRNA in the human gastrointestinal tract by in situ hybridisation. J. Clin. Invest. 93:347-354.

33. Puchelle, E., et al. 1992. Differential localization of cystic fibrosis transmembrane conductance regulator in normal and cystic fibrosis airway epithelium. Am. J. Respir. Cell Mol. Biol. 7:485-491.

34. Berschneider, H.M., et al. 1988. Altered intestinal chloride transport in cystic fibrosis. FASEB J. 2:2625-2629.

35. Hayden, U.L., and Carey, H.V. 1996. Cellular localization of cystic fibrosis transmembrane conductance regulator protein in piglet and mouse intestine. Cell Tissue Res. 283:209-213.

36. Hoogeveen, A.T., et al. 1991. Immunological localization of cystic fibrosis candidate gene products. Exp. Cell Res. 193:435-437.

37. Pasyk, E.A., and Foskett, J.K. 1995. Mutant ( $\Delta$ F508) cystic fibrosis transmembrane conductance regulator $\mathrm{Cl}^{-}$channel is functional when retained in endoplasmic reticulum of mammalian cells. J. Biol. Chem. 270:12347-12350

38. Bradbury, N.A., Cohn, J.A., Venglarik, C.J., and Bridges, R.J. 1994. Biochemical and biophysical identification of cystic fibrosis transmembrane conductance regulator chloride channels as components of endocytic clathrin-coated vesicles. J. Biol. Chem. 269:8296-8302.

39. Zhang, Y., Doranz, B., Yankaskas, J.R., and Engelhardt, J.F. 1995. Genotypic analysis of respiratory mucous sulfation defects in cystic fibrosis. J. Clin. Invest. 96:2997-3004.

40. Jilling, T, and Kirk, K.L. 1996. Cyclic AMP and chloride-dependent regulation of apical constitutive secretory pathway in colonic epithelial cells. J. Biol. Chem. 271:4381-4387.

41. Engelhardt, J.F., et al. 1994. Coupled secretion of chloride and mucus in skin of Xenopus laevis: possible role for CFTR. Am. J. Physiol. 267:C491-C500

42. Montserrat, C., Merten, M., and Figarella, C. 1996. Defective ATPdependent mucin secretion by cystic fibrosis pancreatic epithelial cells. FEBS Lett. 393:264-268.

43. Prince, L.S., Workman, R.B., Jr., and Marchase, R.B. 1994. Rapid endocytosis of the cystic fibrosis transmembrane conductance regulator chloride channel. Proc. Natl. Acad. Sci. USA. 91:5192-5196.

44. Pollard, H.B., et al. 1984. An osmotic mechanism for exocytosis from dissociated chromaffin cell. J. Biol. Chem. 259:1114-1121.

45. Mills, C.L., Pereira, M.M.C., Dormer, R.L., and McPherson, M.A. 1992. An antibody against CFTR-derived peptide incorporated into living submandibular cells, inhibits beta-adrenergic stimulation of mucin secretion. Biochem. Biophys. Res. Commun. 188:1146-1152. 
46. Kuver, R., et al. 1994. Constitutive mucin secretion linked to CFTR expression. Biochem. Biophys. Res. Commun. 203:1457-1462.

47. Inglis, S.K., Corboz, M.R., Taylor, A.E., and Ballard, S.T. 1997. Effect of anion transport inhibition on mucus secretion by airway submucosal glands. Am. J. Physiol. 272:L372-L377.

48. Merlin, D., et al. 1994. ATP-stimulated electrolyte and mucin secretion in the human goblet cell line HT29-Cl.16E. J. Membr. Biol. 137:137-149.

49. Montrose-Rafizadeh, C., Guggino, W.B., and Montrose, M.H. 1991. Cellular differentiation regulates expression of $\mathrm{Cl}^{-}$transport and cystic fibrosis transmembrane conductance regulator mRNA in human intestinal cells. J. Biol. Chem. 266:4495-4499.

50. Rich, D.P., et al. 1990. Expression of cystic fibrosis transmembrane conductance regulator corrects defective chloride channel regulation in cystic fibrosis airway epithelial cells. Nature. 347:358-363.

51. Bebok, Z., et al. 1998. Activation of $\triangle F 508$ CFTR in an epithelial monolayer. Am. J. Physiol. 275:C599-C607.

52. Hollande, E., et al. 1998. Targeting of CFTR protein is linked to the polarization of human pancreatic duct cells in culture. Eur. J. Cell Biol. 76:220-227.

53. Zeiher, B.G., et al. 1995. A mouse model for the $\Delta \mathrm{F} 508$ allele of cystic fibrosis. J. Clin. Invest. 96:2051-2064.

54. Colledge, W.H., et al. 1995. Generation and characterization of a $\Delta F 508$ cystic fibrosis mouse model. Nat. Genet. 10:445-452.

55. French, P.J., et al. 1996. A $\Delta \mathrm{F} 508$ mutation in mouse cystic fibrosis transmembrane conductance regulator results in a temperature-sensitive processing defect in vivo. J. Clin. Invest. 98:1304-1312.

56. Riordan, J.R., et al. 1989. Identification of the cystic fibrosis gene: cloning and characterization of complementary DNA. Science. 245:1066-1073.

57. White, N.L., Higgins, C.F., and Trezise, A.E.O. 1998. Tissue-specific in vivo transcription start sites of the human and murine cystic fibrosis genes. Hum. Mol. Genet. 7:363-369.

58. Mak, V., Jarvi, K.A., Zielenski, J., Durie, P., and Tsui, L.-C. 1997. Higher proportion of intact exon 9 CFTR mRNA in nasal epithelium compared with vas deferens. Hum. Mol. Genet. 6:2099-2107.

59. Moyer, B.D., et al. 1998. Membrane trafficking of the cystic fibrosis gene product, cystic fibrosis transmembrane conductance regulator, tagged with green fluorescent protein in Madin-Darby canine kidney cells. $J$. Biol. Chem. 273:21759-21768.

60. Cooper, S.T, and Millar, N.S. 1997. Host cell-specific folding and assembly of neuronal acetylcholine receptor $\alpha 7$ subunit. J. Neurochem.
68:2140-2151.

61. Saftig, P., et al. 1997. Mice deficient in lysosomal acid phosphatase develop lysosomal storage in the kidney and central nervous system. J. Biol. Chem. 272:18628-18635.

62. Mickle, J.E., et al. 1998. A mutation in the cystic fibrosis transmembrane conductance regulator gene associated with elevated sweat chloride concentrations in the absence of cystic fibrosis. Hum. Mol. Genet. 7:715-727.

63. Rubenstein, R.C., and Zeitlin, P.L. 1998. A pilot clinical trial of oral sodium 4-phenylbutyrate (buphenyl) in $\Delta \mathrm{F} 508$-homozygous cystic fibrosis patients. Am. J. Respir. Crit. Care Med. 157:484-490.

64. Veeze, H.J., et al. 1994. Determinants of mild clinical symptoms in cystic fibrosis patients. J. Clin. Invest. 93:461-466.

65. Kelley, T.J., Thomas, K., Milgram, L.J.H., and Drumm, M.L. 1997. In vivo activation of the cystic fibrosis transmembrane conductance regulator mutant $\Delta$ F508 in murine nasal epithelium. Proc. Natl. Acad. Sci. USA. 94:2604-2608.

66. Webster, P., Vanacore, L., Nairn, A.C., and Marino, C.R. 1994. Subcellular localization of CFTR to endosomes in a ductal epithelium. Am. J. Physiol. 267:C340-C348.

67. Takahashi, A., Watkins, S.C., Howard, M., and Frizzell, R.A. 1996. CFTR dependent membrane insertion is linked to stimulation of the CFTR chloride conductance. Am. J. Physiol. 271:C1887-C1894.

68. Bradbury, N.A., et al. 1992. Regulation of plasma membrane recycling by CFTR. Science. 256:530-532.

69. Lehrich, R.W., Aller, S.G., Webster, P., Marino, C.R., and Forrest, J.N., Jr. 1998. Vasoactive intestinal peptide, forskolin, and genistein increase apical CFTR trafficking in the rectal gland of the spiny dogfish, Squalus acanthias. Acute regulation of CFTR trafficking in an intact epithelium. J. Clin. Invest. 101:737-745.

70. Schwiebert, E.M., et al. 1994. Heterotrimeric G-proteins, vesicle trafficking and CFTR chloride channels. Am. J. Physiol. 267:C272-C281.

71. Chu, C.-S., Trapnell, B.C., Curristin, S., Cutting, G.R., and Crystal, R.G. 1993. Genetic basis of variable exon 9 skipping in cystic fibrosis transmembrane conductance regulator. Nat. Genet. 3:151-156.

72. Johnson, L.G., et al. 1992. Efficiency of gene transfer for restoration of normal airway epithelial function in cystic fibrosis. Nat. Genet. 2:21-25.

73. Dorin, J.R., et al. 1996. A demonstration using mouse models that successful gene therapy for cystic fibrosis requires only partial gene correction. Gene Ther. 3:797-801.

74. Zhang, Y., Jiang, Q., Dudus, L., Yankaskas, J.R., and Engelhardt, J.F. 1998. Vector-specific complementation profiles of two independent primary defects in cystic fibrosis airways. Hum. Gene Ther. 9:635-648. 